\title{
Show cards of the Global Physical Activity Questionnaire (GPAQ) - do they impact validity? A crossover study
}

\author{
Kevin Rudolf ${ }^{1 *}$ (D), Florian Lammer ${ }^{1}$, Gerrit Stassen ${ }^{1,2}$, Ingo Froböse ${ }^{1,3}$ and Andrea Schaller ${ }^{1,2,4}$
}

\begin{abstract}
Background: The Global Physical Activity Questionnaire (GPAQ) is applied internationally as a tool to assess the level of physical activity. The GPAQ was designed as an interview, including the use of show cards, which visualise activities of moderate and intensive physical activity and support the distinction between these intensities. The selfadministered version of the GPAQ is used in the application-oriented research for reasons of economy and practicality. However, the use of show cards often remains unknown.

The aim of the present study was to examine differences in validity between two self-administered versions of the GPAQ with and without show cards.

Methods: In this crossover study, two groups ( $n=54 ; 57.4 \%$ female; $28.3 \pm 12.2$ years) received the GPAQ with or without show cards after 7 days and the respective other version after additional 7 days. For validation, all participants wore an accelerometer (ActiGraph GT3X+) on all 14 days.

Differences between GPAQ versions and accelerometer data were compared by Wilcoxon signed rank test. Additionally, Spearman analyses and Bland-Altman plots were calculated.
\end{abstract}

Results: No statistically significant difference between the GPAQ versions could be found in regard to the accuracy of physical activity assessment ( $p>0.05)$.

Both GPAQ versions show similar correlation coefficients for vigorous physical activity (rho $=0.31-0.42$ ) and sedentary behaviour (rho $=0.29-0.32$ ). No statistically significant correlation was found for physical activity of moderate intensity. The Bland-Altman plots support these results, as both GPAQ versions have the same trends in terms of overestimation and underestimation of physical activity.

Conclusion: The use of show cards had no significant impact on questionnaire validity. Therefore, both GPAQ versions can be applied interchangeably. Nevertheless the exact description of application of the GPAQ is desirable in terms of reproducibility and transparent scientific research.

Keywords: Physical activity assessment, Accelerometry, Instrument psychometrics, Measurement, Methods

\section{Background}

Even though physical activity is widely recognized as a cornerstone of a healthy lifestyle and many campaigns and interventions aim to promote physical activity, the measurement of physical activity including the scientific evaluation of these programs remains a challenge.

\footnotetext{
* Correspondence: k.rudolf@dshs-koeln.de

${ }^{1}$ Institute of Movement Therapy and movement-oriented Prevention and Rehabilitation, German Sport University Cologne, Am Sportpark Müngersdorf 6, 50933 Cologne, Germany

Full list of author information is available at the end of the article
}

Over the last decades a large variety of instruments to assess physical activity emerged [1-5]. Whereas the doubly-labeled water method (DLW) [6] relies on the chemical measures of energy expenditure, others, like accelerometers, record proper accelerations, and still others, like questionnaires, focus on the individual's memory and perception of physical activity.

This diversity of measurement techniques inevitably comes along with different assets and drawbacks regarding validity and feasibility $[1,2,4,5]$. While the DLW 
represents high validity in assessing total energy expenditure, it is a complex and expensive procedure that provides a total value of energy expenditure for a certain time frame but does not give information, e.g., on several individual periods of time or the context of energy expenditure [3, 5, 7]. Questionnaires, on the other side, are considered a more practicable tool to assess physical activity in large samples [2, 5]. Although, disadvantages in its utility are apparent, such as the inaccuracy due to lack of memory, social desirability and other social and cognitive factors $[8-10]$, they can provide insight into the context of physical activity as well as retrospective data over various time frames $[1,11]$. Moreover, they are usually simple to administer, easy to distribute online and inexpensive $[3,5,12]$. Therefore questionnaires are often the method of choice for practice-oriented research [13].

In 2002, the World Health Organization (WHO) initialized its STEPwise approach for surveillance of risk factors for chronic disease (STEPS). In line with STEPS, the Global Physical Activity Questionnaire (GPAQ) was designed to assess physical activity in different settings and cultures around the world. According to the WHO website (https://www.who.int/ncds/surveillance/steps/GPAQ/en/), the GPAQ has been used in more than 100 countries to assess physical activity at work, in leisure time and for transportation purposes. It differentiates between moderate and vigorous physical activity and has an additional question regarding daily sedentary behaviour [14].

In its original version, the GPAQ was designed as an interview which has to be adapted to the respective culture in which it is applied [14]. Previous validation studies showed acceptable reliability $[15,16]$ and validity $[15,17]$ for the GPAQ in various countries. Moreover, self-administered versions of the GPAQ have been validated over the past years showing comparable quality criteria $[18,19]$.

However, the original version of the GPAQ includes so called "show cards", which are adapted to illustrate exemplary physical activities of moderate and vigorous intensity typical for the respective culture [14]. In many studies that use the GPAQ for the assessment of physical activity, it remains unclear whether they use these show cards, though [20-22]. Hence, the question arises whether the validity of the GPAQ changes depending on the application of show cards.

\section{Objective}

The present study aims to examine differences regarding validity between two self-administered versions of the GPAQ with and without show cards.

\section{Methods}

\section{Study design}

The current study was conducted as a randomized crossover trial. Participants were randomized to answer the German version of the GPAQ with show cards depicting examples of moderate and vigorous physical activities ("GPAQ+") or without such show cards ("GPAQ-") after 7 days. After the next 7 days, the two study groups were reversed according to the randomized crossover design (see Fig. 1). In addition, objective physical activity data of all participants were recorded by accelerometry (ActiGraph GT3X+) over the whole investigation period of 14 days $(2 \times 7$ days $)$.

\section{Participants}

A convenience sample was recruited mainly via bulletins at the German Sport University Cologne and different sport clubs in Cologne, Germany. Interested individuals were contacted via email or telephone and given detailed instructions about the study.

Recruitment and data collection were conducted between May and July 2017. Recruitment was closed after more than 50 usable datasets were collected [23].

\section{Eligibility criteria}

Inclusion criteria were the participants' age of at least 18 years, understanding German, and access to the internet on day seven and day 14 to answer the respective version of the GPAQ online. Individuals with acute musculoskeletal diseases or orthopaedic injuries were excluded.

The study was approved by the ethical committee of German Sport University Cologne (reference: 084/2017). Participants received a report on their individual accelerometer measured physical activity after the end of the study. No other incentives for participating in the study were provided. All participants provided written informed consent.

\section{Measures \\ Global Physical Activity Questionnaire (GPAQ)}

The German version of the GPAQ (available at https:// www.who.int/ncds/surveillance/steps/GPAQ/en/) was adapted to a self-administration format by rephrasing the first paragraph, which includes sentences only appropriate in an interview [18]. Consistent with the instruction manual of the GPAQ [24], culturally adapted examples of different physical activities were inserted in the respective questions.

For this study, the GPAQ was delivered in two different versions. GPAQ+ included pictures of work or leisure time activities of moderate or vigorous intensity, while GPAQ- included no pictures. In line with the instruction manual calling for cultural adaptation [24], 


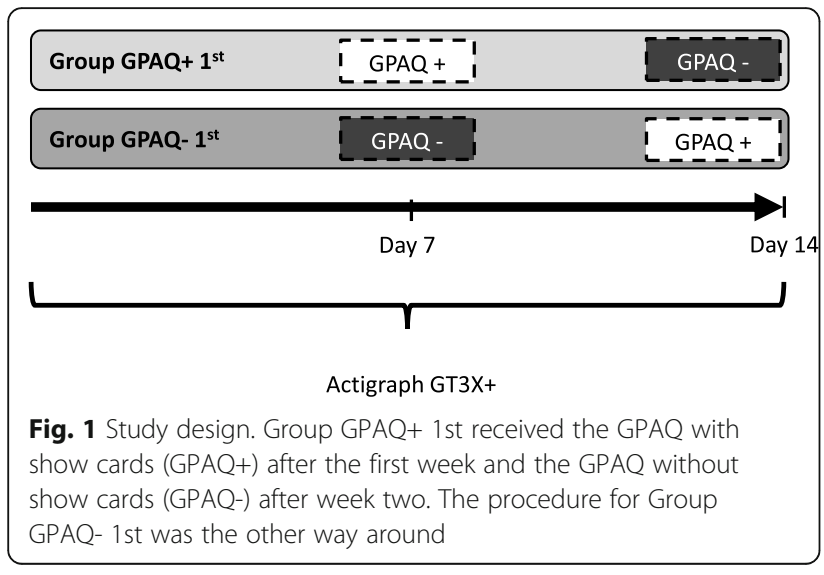

pictures in GPAQ+ were selected to represent typical physical activities of the German population. In order to match the pictures to the respective intensities, the" Compendium of Physical Activities "[25] was used. Activities with 2-6 MET (e.g., working as a mailman, Nordic walking, yoga) were considered moderate intensity, activities with more than 6 MET were considered vigorous intensity (e.g., working as a construction worker, running, basketball). For sedentary behaviour - in line with the instruction manual - no pictures were included in either version. The resulting show cards can be seen in Additional file 1.

For practical reasons, the two versions of the GPAQ were administered via the online survey tool Unipark (Questback GmbH, Cologne, Germany). In this way, transcription errors were avoided and data were automatically available in digital form. A link to the respective GPAQ version was automatically sent by the system to the participants' individual emailaddresses at the morning of day 7 and day 14. Reminder emails were automatically sent if participants did not answer the questionnaire within 2 days after receiving the link.

\section{Actigraph GT3X+}

Objective physical activity was recorded over 14 days with Actigraph GT3X+ accelerometers (ActiGraph, Pensacola, Florida, USA). This type of accelerometer has shown valid results for the assessment of physical activity in adults [26-29].

Participants were instructed to wear the accelerometer on the right-side of their waist for 14 consecutive days, removing them only whilst sleeping or participating in any water-based activity (e.g., showering or swimming). A picture of the application of the accelerometer can be seen in Additional file 2.
Data was collected with a sample rate of $30 \mathrm{~Hz}$ and saved in 30-s epochs.

In line with initializing and handing out the accelerometers, demographic variables (sex, age, body mass index) of all participants were recorded.

\section{Statistical analyses \\ Data preparation}

GPAQ data were cleaned according to the GPAQ analysis guide [24]. In a next step, daily averages (minutes/ day) were calculated for moderate and vigorous physical activity, respectively. For this purpose, physical activity at work, in leisure time and transportation were combined. This procedure was applied to both GPAQ versions, resulting in daily averages of moderate and vigorous physical activity for each version.

The accelerometer data were processed using the ActiLife software (version 6.10.2, ActiGraph, Pensacola, Florida, USA).

Since the data were recorded as counts per minute (CPM), the following cut-points [30] were applied to classify CPM into intensities of physical activity:

- 0-99 CPM: sedentary behaviour,

- 100-1951 CPM: light intensity,

- 1952-5724 CPM: moderate intensity,

- > 5724 CPM: vigorous intensity.

Sixty or more minutes of consecutive zero CPM were marked as non-wear time (allowing for an interruption of maximum 2 minutes with 1-100 CPM) [31]. Individuals were included in the analysis if valid data of at least 3 days with a minimum of 10 hours wear time were available for each of the 2 weeks.

In line with the processing of the GPAQ data, daily averages ( $\mathrm{min} /$ day) of valid days were calculated for moderate and vigorous physical activity (minutes in each activity category divided by the number of recorded days). Data of week one and two were handled separately.

\section{Data analyses}

All statistical analyses were conducted using IBM SPSS Statistics 24.

Descriptive statistics (means, standard deviations, frequencies and percentages) were used to describe demographic characteristics and the data from questionnaires and accelerometers. Chi-squared tests and MannWhitney $U$ tests were used to examine statistically significant differences between groups at baseline and between the included and excluded sample.

Statistical significant differences regarding the validity of the two GPAQ versions were examined using Wilcoxon signed-rank tests. For this purpose, the 
differences of each GPAQ version to the accelerometer data were compared (i.e., GPAQ+ data minus accelerometer data, and GPAQ- data minus accelerometer data).

Spearman's rank correlation coefficients were calculated for the correlation between the daily averages of the accelerometer data and the data from each GPAQ version. The resulting coefficients were interpreted as no correlation (rho $=0-0.09$ ), poor $(\mathrm{rho}=0.10-0.29$ ), fair (rho $=0.30-0.59)$, moderately strong $(r h o=0.6-0.79)$, very strong (rho $=0.8-0.99)$, and perfect correlation $($ rho $=1)$ [32].

In addition, Bland-Altman plots were built to illustrate the agreement of accelerometer and GPAQ data regarding moderate and vigorous physical activity. In a BlandAltman plot, the difference of two measures (y-axis) is plotted against the data of the accelerometer (x-axis) for each participant [33, 34]. The limits of agreement were set at mean difference \pm 1.96 standard deviations. Plots were designed for moderate and vigorous physical activity of both GPAQ versions individually.

The significance level for all analyses was set at $p<$ 0.05 .

\section{Results}

\section{Sample description}

All of the 71 recruited participants were eligible and provided written informed consent. A total of 17 participants were later excluded due to missing data. As a result, data of 54 participants $(57.4 \%$ female, mean age: $28.3 \pm 12.2$ years; mean BMI: $23.2 \pm 3.1 \mathrm{~kg} / \mathrm{m}^{2}$; see Table 1) were analysed. Figure 2 shows the CONSORT flow chart illustrating the progress through the phases of the present study.

No statistically significant differences were found between group GPAQ+ 1st and GPAQ- 1st at baseline regarding sex $(p=0.25)$, age $(p=0.34)$ or BMI $(p=0.51)$. People excluded from the study due to insufficient activity data did not show statistically significant differences to the analysed sample regarding age $(p=0.29)$ or BMI $(p=0.06)$, but were more likely to be men $(p=0.04)$.

Table 2 shows the daily averages of both GPAQ versions as well as data from the accelerometer measurement for the respective time frames. Regardless of operationalization, the sample shows high amounts of moderate to vigorous physical activity of more than 2 hours per day on average.

While no statistically significant differences were found for data on sedentary behaviour, moderate and vigorous intensity data measured by both GPAQ versions differ statistically significant from accelerometer data (all $p<0.05$; see Table 2).

\section{Comparison and association of questionnaire and accelerometer data}

In line with the comparable mean values shown in Table 2, no statistically significant differences could be found between GPAQ+ and GPAQ- for any intensity of physical activity regarding the differences to the accelerometer data (see Table 3; all $p>0.05$ ).

Statistically significant fair correlations were present between $\mathrm{GPAQ}+$ and accelerometer data regarding sedentary behaviour (rho $=0.32 ; p=0.02$ ) and vigorous physical activity (rho $=0.42 ; p<0.01$ ). For GPAQ- and accelerometer data, results were similar regarding sedentary behaviour (rho $=0.29 ; p=0.03$ ) and vigorous physical activity (rho $=0.31 ; p=0.02$ ). In both questionnaire versions, no statistically significant correlations with accelerometer data were found for physical activity of moderate intensity (GPAQ+: rho $=0.19 ; \quad p=0.17$; GPAQ-: rho $=0.18 ; p=0.20$ ).

Figures 3, 4, and 5 show the Bland-Altman plots for the agreement of both GPAQ versions and accelerometer data for vigorous (Fig. 3) and moderate (Fig. 4) physical activity and sedentary behaviour (Fig. 5). The plots illustrate an average over-reporting of vigorous physical activity of $30.3( \pm 35.4)$ minutes per day in the GPAQ+ version and $35.2( \pm 45.5)$ minutes per day in the GPAQ- version in comparison to the accelerometer data. Moderate physical activity, on the other hand, was mostly under-reported with a mean of $21.2( \pm 117.1)$ and $23.1( \pm 89.3)$ minutes per day for GPAQ+ and GPAQ-, respectively. Although the mean differences are small, the wide limits of agreement indicate bigger discrepancies between GPAQ and accelerometer data on an individual level. The same applies for the data on sedentary behaviour. While the mean differences between GPAQ and accelerometer data for sedentary time are quite small (GPAQ-: - $18.3 \pm 150.7 \mathrm{~min} /$ day; GPAQ+: $-9.3 \pm$ $159.6 \mathrm{~min} /$ day), the limits of agreement are wide as well.

Table 1 Sample characteristics

\begin{tabular}{|c|c|c|c|c|}
\hline & Total sample & Group GPAQ+ 1st & Group GPAQ- 1st & $p$ \\
\hline Sex [female] n (\%) & $31(57.4)$ & $17(65.4)$ & $14(50.0)$ & $0.25^{1}$ \\
\hline Age [years] mean (SD) & $28.3(12.2)$ & $26.1(8.9)$ & $30.3(14.6)$ & $0.34^{2}$ \\
\hline BMI $\left[\mathrm{kg} / \mathrm{m}^{2}\right)$ mean $(\mathrm{SD})$ & $23.2(3.1)$ & $23.0(3.3)$ & $23.3(3.0)$ & $0.51^{2}$ \\
\hline
\end{tabular}

${ }^{1}$ Chi-squared test; ${ }^{2}$ Mann-Whitney $\mathrm{U}$ test 


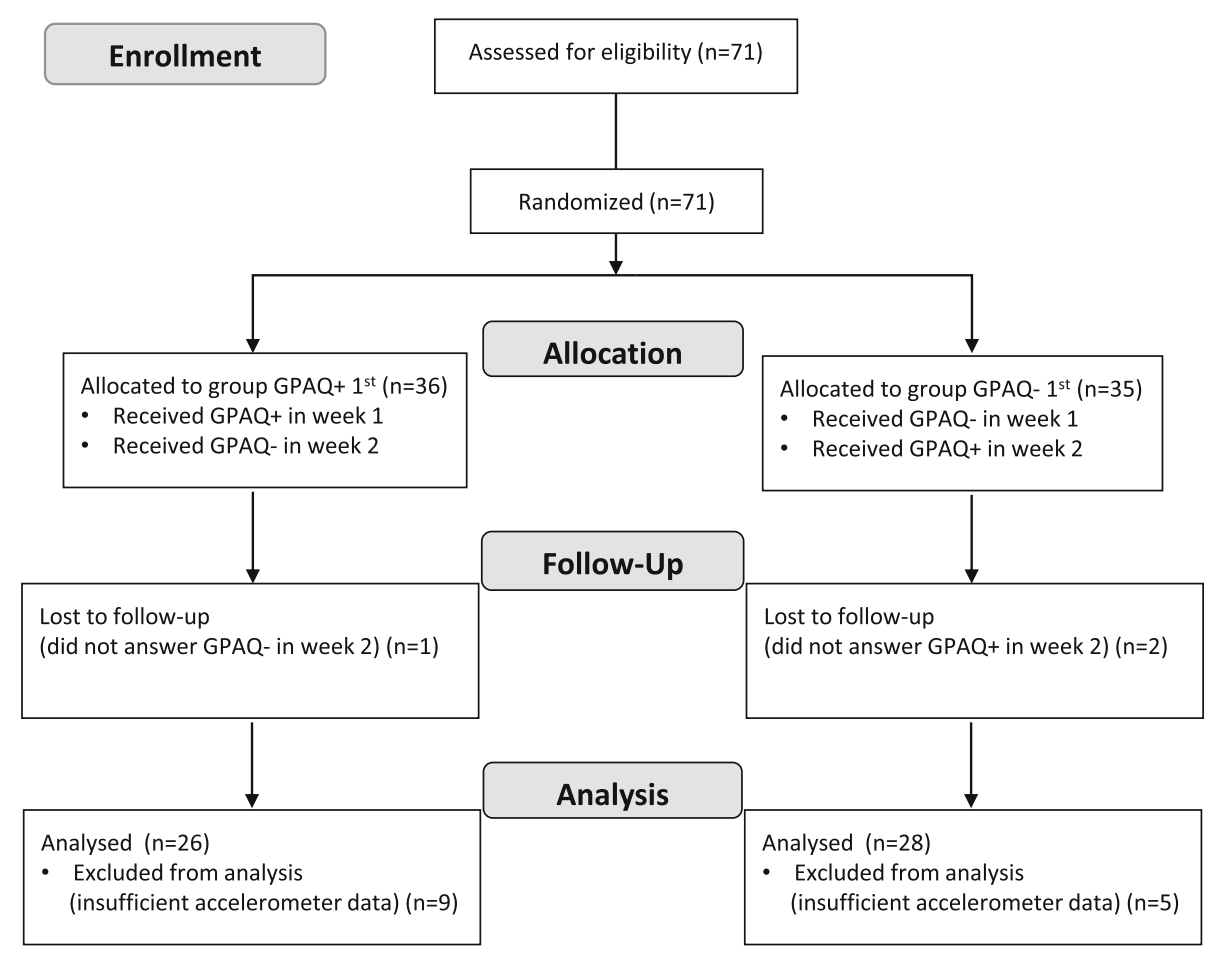

Fig. 2 Flow chart of participation progress

\section{Discussion}

\section{Interpretation}

To our knowledge, the present study is the first examining possible differences in validity of the GPAQ depending on the application of show cards. Comparing the questionnaire data to simultaneously recorded accelerometer data, similar values of validity could be found. While the data show similar fair correlations of both GPAQ versions to the respective data from the accelerometry, no statistically significant associations are present for physical activity of moderate intensity. In addition, Bland-Altman plots and Wilcoxon signed-rank tests show similar patterns of over- and under-reporting of physical activity in both GPAQ versions.

Overall, the results of the present study show that the application of the GPAQ without show cards does not inflict validity in the current sample. Whether or not show cards were used, the correlation of the GPAQ and accelerometer data was fair. This result goes in line with previous validation studies of the GPAQ that show poor to fair correlation to accelerometry, as well $[18,19,35]$. Hence, the use of the GPAQ without show cards deems equally valid as the application with show cards. This finding improves the feasibility of the GPAQ since the preparation and cultural adaption of show cards seems not to be necessary anymore. Moreover, it indicates that the results of previously conducted studies which did not use or report the use of show cards can be compared with studies which used the show cards.

Although the mean differences to the accelerometer data were relatively small, the differences on an individual level were very high for some participants who over-

Table 2 Data on physical activity measured by GPAQ+, GPAQ-, and accelerometer

\begin{tabular}{|c|c|c|c|}
\hline$n=54$ & GPAQ + & Accelerometer & $p^{1}$ \\
\hline Moderate intensity [min/d] mean (SD) & $86.8(90.5)$ & $109.9(29.7)$ & $0.01^{*}$ \\
\hline Vigorous intensity [min/d] mean (SD) & $48.7(47.9)$ & $13.4(11.3)$ & $<0.01 *$ \\
\hline Sedentary behaviour [min/d] mean (SD) & $420.8(154.2)$ & $439.2(78.5)$ & 0.61 \\
\hline$n=54$ & GPAQ - & Accelerometer & $p^{1}$ \\
\hline Moderate intensity $[\mathrm{min} / \mathrm{d}]$ mean (SD) & $88.6(121.0)$ & $109.9(33.1)$ & $<0.01 *$ \\
\hline Vigorous intensity [min/d] mean (SD) & $42.4(36.1)$ & $12.1(9.4)$ & $<0.01 *$ \\
\hline Sedentary behaviour [min/d] mean (SD) & $426.9(163.3)$ & $436.2(81.6)$ & 0.83 \\
\hline
\end{tabular}

${ }^{1}$ Wilcoxon signed-rank tests; ${ }^{*}$ statistically significant $(p<0.05)$ 
Table 3 Mean differences of both GPAQ versions to accelerometer data

\begin{tabular}{llll}
\hline$n=54$ & Difference: GPAQ+ to accelerometer & Difference: GPAQ- to accelerometer & $p^{1}$ \\
\hline Moderate intensity $[\mathrm{min} / \mathrm{d}]$ mean (SD) & $-23.1(89.3)$ & $-21.3(117.1)$ & 0.33 \\
Vigorous intensity $[\mathrm{min} / \mathrm{d}]$ mean (SD) & $35.2(45.5)$ & $30.3(35.4)$ & 0.40 \\
Sedentary behaviour $[\mathrm{min} / \mathrm{d}]$ mean (SD) & $-18.3(150.7)$ & $-9.3(159.6)$ & 0.32 \\
\hline
\end{tabular}

${ }^{1}$ Wilcoxon signed-rank tests

or underestimated their moderate to vigorous physical activity by more than 2 hours a day. This goes in line with previous studies which showed that overestimation of physical activity [36-38] and underestimation of sedentary behaviour $[39,40]$ are a big challenge in subjective physical activity measurements. In our study, a statistically significant under-reporting of daily moderate physical activity of about $21-23 \mathrm{~min}$ was present, as well as a statistically significant over-reporting of daily vigorous physical activity of about 30-35 min. Extrapolated to a week, the higher estimates of vigorous physical activity are more crucial than the under-reporting of moderate physical activity since already $75 \mathrm{~min}$ of vigorous physical activity a week are enough to achieve the recommended amount of physical activity [41]. Although the majority of the present sample was achieving the
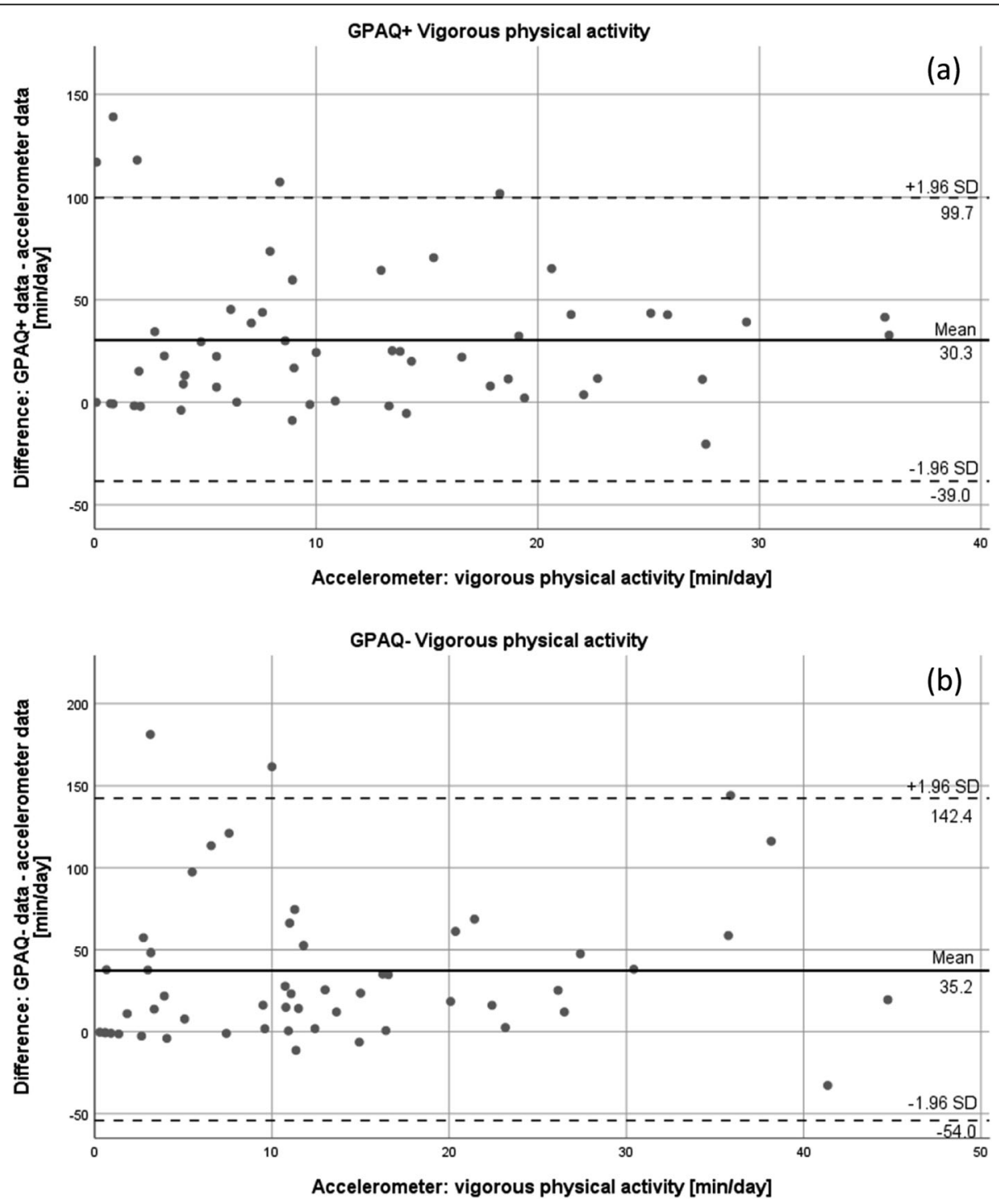

Fig. 3 Bland-Altman plots for vigorous physical activity for (a) GPAQ+ and (b) GPAQ- 

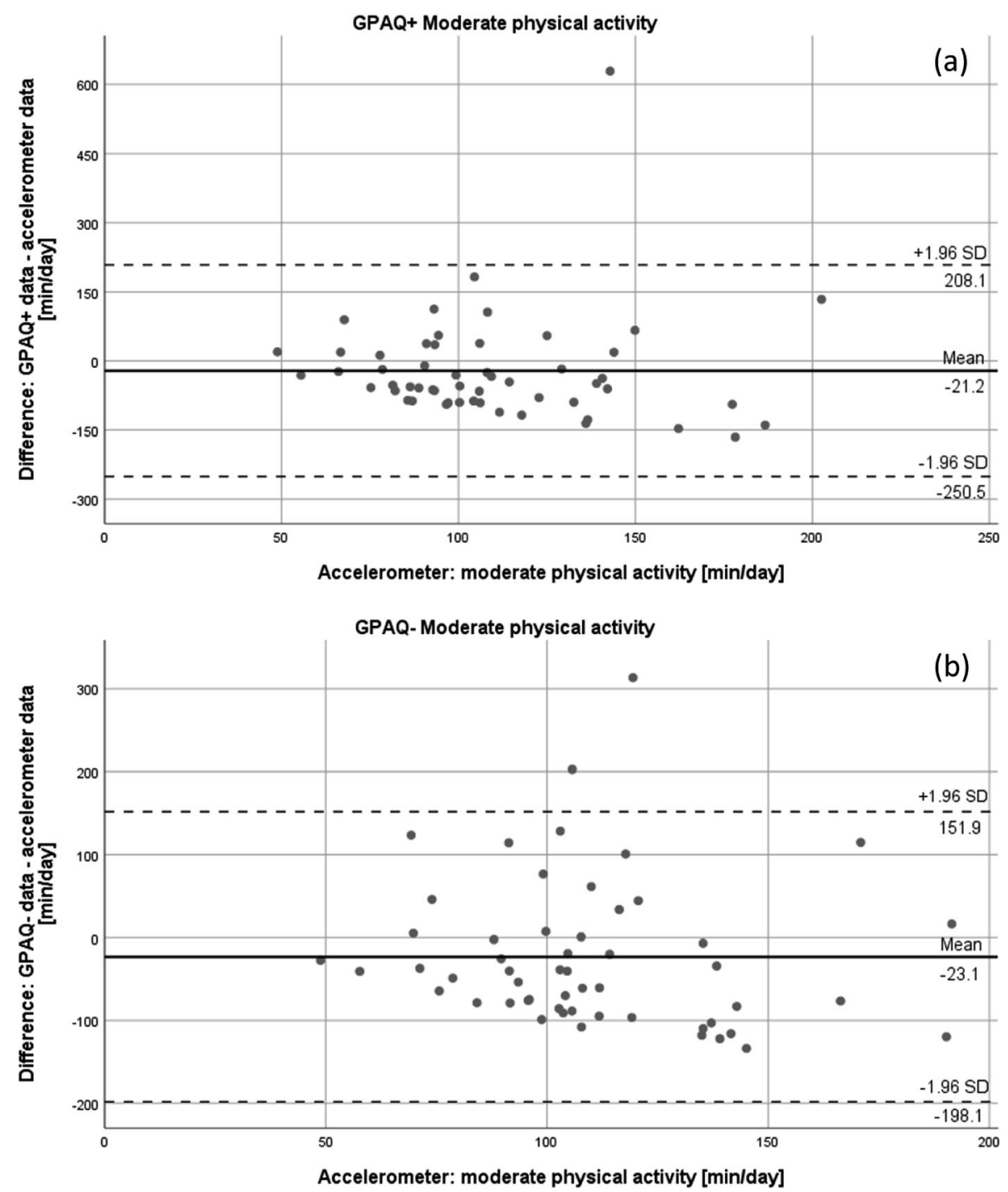

Fig. 4 Bland Altman plots for moderate physical activity for (a) GPAQ+ and (b) GPAQ-

recommendations regardless of this discrepancy, these results hint at potential challenges within other, more inactive samples. The additional show cards are intended to show examples of physical activity and in this way help people to identify relevant behaviour and accurately estimate the intensity of physical activity. Since no difference for the application of show cards was found, one might argue that the problem does not lay within the physical activity intensities but in the estimation of the respective time frames [42]. Although the questionnaires ask for uninterrupted activities that lasts for at least 10 minutes, it might be hard for respondents to estimate the duration of activities that have breaks in it. As an example, one might say, that a person who engages in soccer for $90 \mathrm{~min}$ is physically active for $90 \mathrm{~min}$ as well. However, due to breaks within the game (fouls, throwins, corners etc.), the duration of physical activity normally does not exceed 60 min [43]. An accelerometer on the other hand, would provide a more accurate estimation since it relies on proper acceleration signals and, hence, only tracks real movement. To improve accuracy of self-reports, further research should focus on the implication of phrases which inform participants about these problems. Additionally, for the field of sedentary behaviour research, phrases suggesting to calculate sedentary time by counting the waking hours and subtracting hours in which people do not engage in physical activity of at least light intensity, might be a possible way to go for.

\section{Strengths and limitations}

A limitation of the present study is the composition of the convenience sample. Since recruitment was conducted mainly via bulletins in the German Sports 

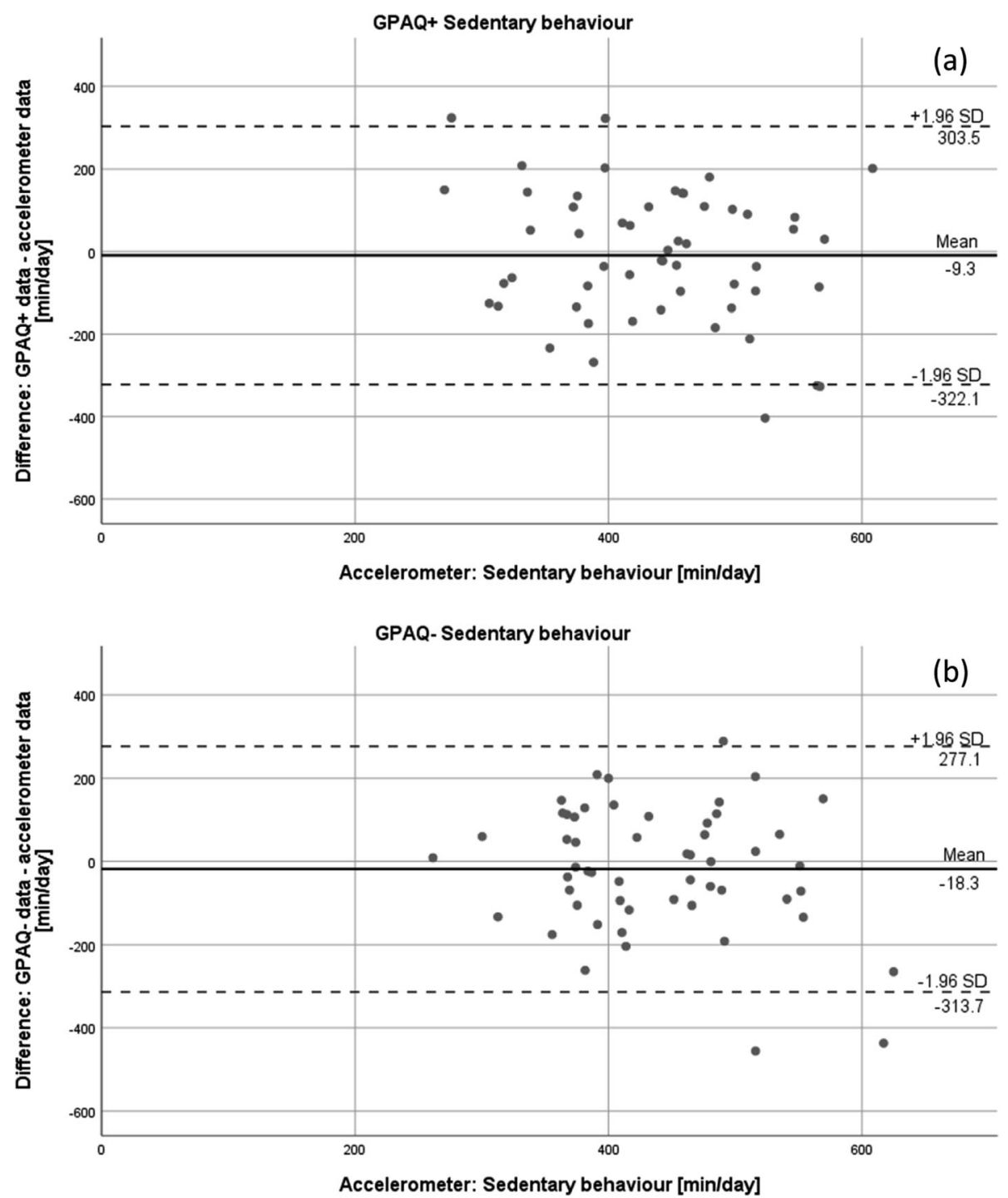

Fig. 5 Bland-Altman plots for sedentary behaviour for (a) GPAQ+ and (b) GPAQ-

University and several sports clubs, the resulting sample had a high level of physical activity. This could have an impact on the results since the sample might be more aware of the intensity of physical activity due to their sports background and, hence, does not need additional examples in form of show cards to assess intensity correctly. The question arises whether a less active sample would produce similar results or benefit more from the examples provided by the show cards.

Another limitation is the selection of activities depicted in the show cards. Although we chose activities by using the" Compendium of Physical Activities "[25], work situations and leisure time activities are manifold and obviously not all of them could be depicted due to limited space. The formal classification may not reflect the individual performance and the resulting physical strain while performing the activity [42]. A soccer match can be of vigorous or moderate intensity depending on the individual's engagement and position within the game (e.g., goal keeper vs. midfielder). Hence, participants still had to compare their activities with those depicted in the show cards, possibly resulting in misclassification intensity-wise.

A strength of the current study is the crossover design. Due to the two groups answering the GPAQ+ and GPAQ- in different weeks, effects of test repetition and sequence-effects were ruled out. Moreover, the simultaneous application of the accelerometer can be seen as an additional strength of the study. By comparing the questionnaires in terms of validity against accelerometry, we collected more information on the similarities between the GPAQ versions than by just filling out each 
questionnaire. In this way, the current study provides comprehensive validity data for the application of the GPAQ with and without show cards. However, the processing of the Actigraph GT3X+ data inherits possible limitations, as well. Since the conversion of the CPM into activity data relies on special cut-points, it cannot be ruled out that the application of other cut-points might result in different amounts of moderate and vigorous physical activity [44]. Cut-points, e.g., with lower CPM-thresholds for vigorous physical activity would possibly result in less under-reporting of moderate physical activity and less over-reporting of vigorous physical activity. However, we used the cut-points of Freedson et al. [30] since they are widely used in the existing literature and most of the other frequently used cut-points for adults inherit very similar thresholds for vigorous physical activity [45].

\section{Conclusion}

The measurement of physical activity for scientific purposes is a challenge that moves between two poles, validity and feasibility. The current study shows that the application of the GPAQ without show cards is more practicable and has no negative effect on the questionnaire's validity in the target sample. Hence, the GPAQ can be used without show cards in practice-oriented research in young, healthy and physically active samples. Further research with different and less active target groups is needed.

\section{Supplementary information}

Supplementary information accompanies this paper at https://doi.org/10. 1186/s12889-020-8312-x

Additional file 1. Illustration of the GPAQ show cards.

Additional file 2. Illustration of the application of the accelerometer.

\section{Abbreviations}

BMI: Body mass index; CPM: Counts per minute; DLW: Doubly-labeled water method; GPAQ: Global Physical Activity Questionnaire; GPAQ: Global Physical Activity Questionnaire without show cards; GPAQ+: Global Physical Activity Questionnaire with show cards; MET: Metabolic equivalent of task; STEPS: STEPwise approach for surveillance of risk factors for chronic disease; WHO: World Health Organization

\section{Acknowledgements}

The authors thank all participants for taking part in the study. The authors thank the German Federal Ministry of Education and Research for funding the cross-cutting issue "physical activity" in the research association TRISEARCH [reference: 01EL1425A].

\section{Authors' contributions}

KR and FL conceived the idea of the study. KR, FL, AS and GS developed the study design. FL recruited the participants and collected the data. KR and FL extracted and analyzed the data. KR drafted the manuscript. KR, AS, IF, GS and $\mathrm{FL}$ participated in the interpretation of results and revised the manuscript. All authors read and approved the final manuscript.

\section{Funding}

This work was supported by the German Federal Ministry of Education and Research [reference: 01EL1425A].

\section{Availability of data and materials}

The datasets used and analyzed during the current study are available from the corresponding author on reasonable request.

\section{Ethics approval and consent to participate}

The study was approved by the ethical committee of German Sport University Cologne (reference: 084/2017). All participants provided written informed consent.

\section{Consent for publication}

Not applicable.

\section{Competing interests}

The authors declare no competing interest concerning this paper.

\section{Author details}

${ }^{1}$ Institute of Movement Therapy and movement-oriented Prevention and Rehabilitation, German Sport University Cologne, Am Sportpark Müngersdorf 6, 50933 Cologne, Germany. ${ }^{2}$ Working group physical activity-related prevention research, German Sport University Cologne, Am Sportpark Müngersdorf 6, 50933 Cologne, Germany. ${ }^{3}$ Center for Health and Physical Activity, German Sport University Cologne, Am Sportpark Müngersdorf 6, 50933 Cologne, Germany. ${ }^{4}$ IST-University of Applied Sciences, Erkrather Straße 220 a-c, 40233 Düsseldorf, Germany.

Received: 16 August 2019 Accepted: 3 February 2020

Published online: 12 February 2020

\section{References}

1. Ainsworth B, Cahalin L, Buman M, Ross R. The current state of physical activity assessment tools. Prog Cardiovasc Dis. 2015;57:387-95. https://doi. org/10.1016/j.pcad.2014.10.005.

2. Müller $C$, Winter $C$, Rosenbaum D. Aktuelle objektive Messverfahren zur Erfassung körperlicher Aktivität im Vergleich zu subjektiven Erhebungsmethoden [Current Objective Techniques for Physical Activity Assessment in Comparison with Subjective Methods]. Deutsche Zeitschrift für Sportmedizin. 2010:61:11-8.

3. Vanhees L, Lefevre J, Philippaerts R, Martens M, Huygens W, Troosters T, Beunen G. How to assess physical activity? How to assess physical fitness? Eur J Cardiovasc Prev Rehabil. 2005;12:102-14. https://doi.org/10.1097/01.hjr. 0000161551.73095.9c.

4. McClung HL, Ptomey LT, Shook RP, Aggarwal A, Gorczyca AM, Sazonov ES, et al. Dietary intake and physical activity assessment: current tools, techniques, and Technologies for use in adult populations. Am J Prev Med. 2018;55:e93-e104. https://doi.org/10.1016/j.amepre.2018.06.011.

5. Welk G, Morrow J, Saint-Maurice P. Measures Registry User Guide: Individual Physical Activity. 2017. http://www.nccor.org/wp-content/uploads/sites/2/2 017/NCCOR_MR_User_Guide_Individual_PA-FINAL.pdf. Accessed 6 Jul 2019.

6. Schoeller DA, van Santen E. Measurement of energy expenditure in humans by doubly labeled water method. J Appl Physiol Respir Environ Exerc Physiol. 1982:53:955-9. https://doi.org/10.1152/jappl.1982.53.4.955.

7. Westerterp KR. Doubly labelled water assessment of energy expenditure: principle, practice, and promise. Eur J Appl Physiol. 2017;117:1277-85. https://doi.org/10.1007/s00421-017-3641-x.

8. Adams SA, Matthews CE, Ebbeling CB, Moore CG, Cunningham JE, Fulton J, Hebert JR. The effect of social desirability and social approval on self-reports of physical activity. Am J Epidemiol. 2005;161:389-98. https://doi.org/10. 1093/aje/kwi054.

9. Coughlin SS. Recall bias in epidemiologic studies. J Clin Epidemiol. 1990;43: 87-91.

10. Durante $R$, Ainsworth $B E$. The recall of physical activity: using a cognitive model of the question-answering process. Med Sci Sports Exerc. 1996;28: 1282-91.

11. Helmerhorst HJF, Brage S, Warren J, Besson H, Ekelund U. A systematic review of reliability and objective criterion-related validity of physical activity questionnaires. Int J Behav Nutr Phys Act. 2012;9:103. https://doi.org/10. 1186/1479-5868-9-103. 
12. Sylvia $L G$, Bernstein EE, Hubbard JL, Keating L, Anderson EJ. Practical guide to measuring physical activity. J Acad Nutr Diet. 2014;114:199-208. https:// doi.org/10.1016/j.jand.2013.09.018.

13. Castillo-Retamal M, Hinckson EA. Measuring physical activity and sedentary behaviour at work: a review. Work. 2011;40:345-57. https://doi.org/10.3233/ WOR-2011-1246

14. Armstrong T, Bull F. Development of the World Health Organization global physical activity questionnaire (GPAQ). J Public Health. 2006;14:66-70. https://doi.org/10.1007/s10389-006-0024-x.

15. Herrmann SD, Heumann KJ, Der Ananian CA, Ainsworth BE. Validity and reliability of the global physical activity questionnaire (GPAQ). Meas Phys Educ Exerc Sci. 2013;17:221-35. https://doi.org/10.1080/1091367X.2013.805139.

16. Bull FC, Maslin TS, Armstrong T. Global physical activity questionnaire (GPAQ): nine country reliability and validity study. J Phys Act Health. 2009;6: 790-804.

17. Cleland CL, Hunter RF, Kee F, Cupples ME, Sallis JF, Tully MA. Validity of the global physical activity questionnaire (GPAQ) in assessing levels and change in moderate-vigorous physical activity and sedentary behaviour. BMC Public Health. 2014;14:1255. https://doi.org/10.1186/1471-2458-14-1255.

18. Wanner M, Hartmann C, Pestoni G, Martin BW, Siegrist M, Martin-Diener E. Validation of the global physical activity questionnaire for selfadministration in a European context. BMJ Open Sport Exerc Med. 2017;3: e000206. https://doi.org/10.1136/bmjsem-2016-000206.

19. Chu AHY, Ng SHX, Koh D, Müller-Riemenschneider F. Reliability and validity of the self- and interviewer-administered versions of the global physical activity questionnaire (GPAQ). PLoS One. 2015. https://doi.org/10.1371/ journal.pone.0136944.

20. Tomaz SA, Lambert EV, Karpul D, Kolbe-Alexander TL. Cardiovascular fitness is associated with bias between self-reported and objectively measured physical activity. Eur J Sport Sci. 2016;16:149-57. https://doi.org/10.1080/ 17461391.2014.987323.

21. Sitthipornvorakul $E$, Janwantanakul $P$, van der Beek AJ. Correlation between pedometer and the global physical activity questionnaire on physical activity measurement in office workers. BMC Res Notes. 2014;7:280. https:/ doi.org/10.1186/1756-0500-7-280.

22. Watson ED, MNM $\vee$ P, Jones RA, Norris SA, Micklesfield LK. Are south African mothers moving? Patterns and correlates of physical activity and sedentary behavior in pregnant black south African women. J Phys Act Health. 2017; 14:329-35. https://doi.org/10.1123/jpah.2016-0388.

23. Terwee CB, Mokkink LB, van Poppel MNM, Chinapaw MJM, van Mechelen W, de Vet HCW. Qualitative attributes and measurement properties of physical activity questionnaires: a checklist. Sports Med. 2010;40:525-37. https://doi.org/10.2165/11531370-000000000-00000.

24. Global Physical Activity Questionnaire (GPAQ) Analysis Guide. 2002. https:// www.who.int/ncds/surveillance/steps/resources/GPAQ_Analysis_Guide.pdf.

25. Ainsworth BE, Haskell WL, Herrmann SD, Meckes N, Bassett DR, Tudor-Locke C, et al. 2011 compendium of physical activities: a second update of codes and MET values. Med Sci Sports Exerc. 2011;43:1575-81. https://doi.org/10. 1249/MSS.0b013e31821ece12.

26. Liu A-I, Li Y-p, Song J, Pan H, Han X-m, Ma G-s. Study on the validation of the computer science application's activity monitor in assessing the physical activity among adults using doubly labeled water method. Zhonghua Liu Xing Bing Xue Za Zhi. 2005;26:197-200.

27. Kelly LA, McMillan DG, Anderson A, Fippinger M, Fillerup G, Rider J. Validity of actigraphs uniaxial and triaxial accelerometers for assessment of physical activity in adults in laboratory conditions. BMC Med Phys. 2013;13:5. https:// doi.org/10.1186/1756-6649-13-5.

28. Chomistek AK, Yuan C, Matthews CE, Troiano RP, Bowles HR, Rood J, et al. Physical activity assessment with the ActiGraph GT3X and doubly labeled water. Med Sci Sports Exerc. 2017;49:1935-44. https://doi.org/10.1249/MSS. 0000000000001299.

29. Aadland E, Ylvisåker E. Reliability of the Actigraph GT3X+ accelerometer in adults under free-living conditions. PLoS One. 2015;10:e0134606. https://doi. org/10.1371/journal.pone.0134606.

30. Freedson PS, Melanson E, Sirard J. Calibration of the computer science and applications, Inc accelerometer. Med Sci Sports Exerc. 1998;30:777-81.

31. Troiano RP. Large-scale applications of accelerometers: new frontiers and new questions. Med Sci Sports Exerc. 2007;39:1501. https://doi.org/10.1097/ mss.0b013e318150d42e.

32. Chan YH. Biostatistics 104: correlational analysis. Singap Med J. 2003;44: 614-9.
33. Bland JM, Altman DG. Statistical methods for assessing agreement between two methods of clinical measurement. Lancet. 1986;1:307-10.

34. Krouwer JS. Why Bland-Altman plots should use $X$, not $(Y+X) / 2$ when $X$ is a reference method. Stat Med. 2008;27:778-80. https://doi.org/10.1002/sim.3086.

35. Alkahtani SA. Convergent validity: agreement between accelerometry and the global physical activity questionnaire in college-age Saudi men. BMC Res Notes. 2016;9:436. https://doi.org/10.1186/s13104-016-2242-9.

36. Lee PH, Macfarlane DJ, Lam TH, Stewart SM. Validity of the International Physical Activity Questionnaire Short Form (IPAQ-SF): a systematic review. Int J Behav Nutr Phys Act. 2011;8:115. https://doi.org/10.1186/1479-5868-8-115.

37. Prince SA, Adamo KB, Hamel ME, Hardt J, Connor Gorber S, Tremblay M. A comparison of direct versus self-report measures for assessing physical activity in adults: a systematic review. Int J Behav Nutr Phys Act. 2008:5:56 https://doi.org/10.1186/1479-5868-5-56.

38. Dowd KP, Szeklicki R, Minetto MA, Murphy MH, Polito A, Ghigo E, et al. A systematic literature review of reviews on techniques for physical activity measurement in adults: a DEDIPAC study. Int J Behav Nutr Phys Act. 2018; 15:15. https://doi.org/10.1186/s12966-017-0636-2

39. Harvey JA, Chastin SFM, Skelton DA. How sedentary are older people? A systematic review of the amount of sedentary behavior. J Aging Phys Act. 2015;23:471-87. https://doi.org/10.1123/japa.2014-0164.

40. Copeland JL, Ashe MC, Biddle SJ, Brown WJ, Buman MP, Chastin S, et al Sedentary time in older adults: a critical review of measurement, associations with health, and interventions. Br J Sports Med. 2017:51:1539. https://doi.org/10.1136/bjsports-2016-097210.

41. World Health Organization. Global recommendations on physical activity for health. Genève: World Health Organization; 2010.

42. Matthews CE, Moore SC, George SM, Sampson J, Bowles HR. Improving selfreports of active and sedentary behaviors in large epidemiologic studies. Exerc Sport Sci Rev. 2012;40:118-26. https://doi.org/10.1097/JES. 0b013e31825b34a0.

43. Siegle M, Lames M. Game interruptions in elite soccer. J Sports Sci. 2012;30: 619-24. https://doi.org/10.1080/02640414.2012.667877.

44. Smith MP, Standl M, Heinrich J, Schulz H. Accelerometric estimates of physical activity vary unstably with data handling. PLoS One. 2017;12: e0187706. https://doi.org/10.1371/journal.pone.0187706.

45. Migueles JH, Cadenas-Sanchez C, Ekelund U, Delisle Nyström C, MoraGonzalez J, Löf M, et al. Accelerometer data collection and processing criteria to assess physical activity and other outcomes: A systematic review and practical considerations. Sports Med. 2017;47:1821-45. https://doi.org/ 10.1007/s40279-017-0716-0.

\section{Publisher's Note}

Springer Nature remains neutral with regard to jurisdictional claims in published maps and institutional affiliations.

Ready to submit your research? Choose BMC and benefit from

- fast, convenient online submission

- thorough peer review by experienced researchers in your field

- rapid publication on acceptance

- support for research data, including large and complex data types

- gold Open Access which fosters wider collaboration and increased citations

- maximum visibility for your research: over $100 \mathrm{M}$ website views per year

At $\mathrm{BMC}$, research is always in progress.

Learn more biomedcentral.com/submission 